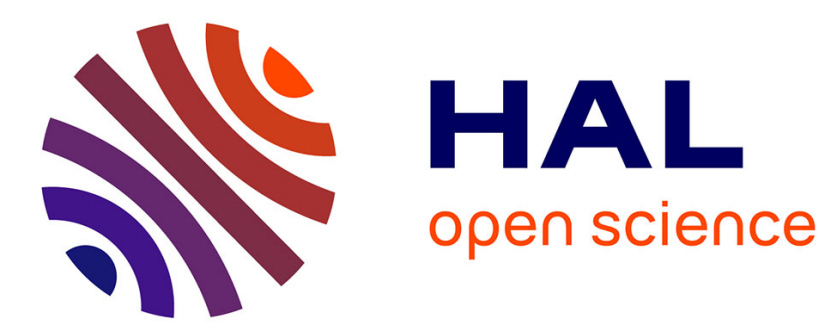

\title{
Growth and instability in a small open economy with debt
}

Leonor Modesto, Carine Nourry, Thomas Seegmuller, Alain Venditti

\section{To cite this version:}

Leonor Modesto, Carine Nourry, Thomas Seegmuller, Alain Venditti. Growth and instability in a small open economy with debt. 2020. halshs-02545137

\author{
HAL Id: halshs-02545137 \\ https://shs.hal.science/halshs-02545137 \\ Preprint submitted on 16 Apr 2020
}

HAL is a multi-disciplinary open access archive for the deposit and dissemination of scientific research documents, whether they are published or not. The documents may come from teaching and research institutions in France or abroad, or from public or private research centers.
L'archive ouverte pluridisciplinaire HAL, est destinée au dépôt et à la diffusion de documents scientifiques de niveau recherche, publiés ou non, émanant des établissements d'enseignement et de recherche français ou étrangers, des laboratoires publics ou privés. 


\section{amse}

école d'économie d'aix-marseille aix-marseille school of economics

\section{Working Papers / Documents de travail}

Growth and instability in a small open economy with debt

Leonor Modesto

Carine Nourry

Thomas Seegmuller

Alain Venditti 


\title{
Growth and instability in a small open economy with debt*
}

\author{
Leonor MODESTO ${ }^{\dagger}$ \\ UCP, Catolica Lisbon School of Business and Economics 83 IZA \\ Carine NOURRY $\ddagger$ \\ Aix-Marseille Univ., CNRS, EHESS, Centrale Marseille, AMSE \\ Thomas SEEGMULLER ${ }^{\S}$ \\ Aix-Marseille Univ., CNRS, EHESS, Centrale Marseille, AMSE \\ and \\ Alain VENDITTI \\ Aix-Marseille Univ., CNRS, EHESS, Centrale Marseille, AMSE 6 \\ EDHEC Business School
}

\begin{abstract}
The relationship between public debt, growth and volatility is investigated in a Barro-type (1990) endogenous growth model, with three main features: we consider a small open economy, international borrowing is constrained and households have taste for domestic public debt. Therefore, capital, public debt and the international asset are not perfect substitutes and the economy is characterized by an investment multiplier. Whatever the level of the debt-output

${ }^{*}$ This work was supported by French National Research Agency Grants ANR-08-BLAN0245-01 and ANR-17-EURE-0020. We thank T. Lloyd-Braga, X. Raurich and G. Sorger for useful comments and suggestions. We also thank C. Lis Castiblanco for her help concerning the numerical simulations. This paper also benefited from presentations at the "19th Annual SAET Conference", Ischia, June 30-July 6, 2019, and at the Workshop "Tribute to Carine Nourry", AMSE, November 8, 2019.

†Email: lrm@ucp.pt.

¥This work has been carried out while our dear friend and colleague Carine Nourry was fighting against cancer. She passed away on June 7, 2019. We are forever indebted to her. This paper is in her memory.

$\S$ Email: thomas.seegmuller@univ-amu.fr.

${ }^{\top}$ Corresponding author: AMSE - 5 Boulevard Bourdet - CS 50498 - 13205 Marseille Cedex 01. Email: alain.venditti@univ-amu.fr.
\end{abstract}


ratio, the existing BGP features expectation-driven fluctuations. If the debt-output ratio is low enough, there is also a second BGP with a lower growth rate. Hence, a lower debt does not stabilize the economy with credit market imperfections. However, a high enough taste for domestic public debt may rule out the BGP with lower growth. This means that if the share of public debt hold by domestic households is high enough, global indeterminacy does not occur.

Keywords: Small open economy, public debt, credit constraint, indeterminacy.

Journal of Economic Literature Classification Numbers: E32, F43, H63 


\section{Introduction}

Following the last financial crisis, debt levels have increased dramatically in many advanced countries raising the problem of debt sustainability and of possible bankruptcy. The control of the growth rate of public spending has then become a major concern for economists and policy-makers, while the average debt-to-GDP ratio has increased in one decade since the 2008 crisis by more than 20 percentage points. Yet, the situation is quite heterogeneous across countries. While Greece has faced huge solvency problems after its debt-to-GDP ratio exceeded $150 \%$ in 2010, Japan does not seem to face similar difficulties with a debt-to-GDP ratio that has recently reached $250 \%$. These various experiences illustrate the idea that debt sustainability is a complex question. ${ }^{1}$

In this paper we address this complexity of public debt financing, reexamining two main questions. On the one hand we study the relationship between the level of debt and growth, and on the other hand we highlight the link between macroeconomic stability and debt. In comparison to the recent literature, we introduce three additional dimensions. First, while most existing papers are concerned with closed economies (Chéron et al. (2019), Futagami et al. (2008), Maebayashi et al. (2017), Minea and Villieu (2013)), in this paper we consider instead a small open economy. Like us, Morimoto et al. (2017) also addressed the case of a small open economy. However, these authors assume that the different assets, productive capital and domestic and external debt, are perfect substitutes. Therefore, in their work there is no portfolio choice for the households and only the level of total asset holdings plays a role.

Second, following empirical evidence (Chung and Turnovsky (2010), Manova (2008)), we assume that borrowing on the international market is

\footnotetext{
${ }^{1}$ This is highlighted in the paper by Collard et al. (2015), which provides a model where the amount investors are willing to lend to a country's government depends on its expected primary surplus, the country level and volatility of growth, and the level of debt they expect the government will be able to raise in the future with the purpose of servicing the debt it seeks to raise today. Based on that, they propose a measure of maximum sustainable government debt for advanced economies that strongly varies across countries.
} 
limited. The loans provided by the rest of the world are constrained and collateralized by the capital invested in the home country. ${ }^{2}$ As in Fahri and Tirole (2012), Kiyotaki and Moore (1997) or Hirano and Yanagawa (2017), such a credit constraint generates an investment multiplier, which will play a key role inducing expectation-driven fluctuations.

Finally, empirical evidence also highlights that in the Euro area and in the US around $50 \%$ of public debt is held by non-residents, while in Japan and in the UK only $4 \%$ and $31 \%$ respectively of the national public debt is held by non-residents. This means that almost the totality of Japanese debt and the majority of the UK debt are held by domestic institutions. Note that, such a characteristic could provide an explanation for the strong sustainability of the Japanese debt. In order to take into account this variety of configurations, we introduce domestic public bonds in the utility function in order to be able to measure the degree of the taste for domestic public bonds, and quantify its effects.

The aim of this paper is to introduce these three features into a dynamic model with infinitely-lived households where, following Barro (1990), endogenous growth is obtained through public expenditures that improve production and are financed both by taxes on income and public debt. Considering a small open economy, loans can be contracted from the rest of the world. However, because of a credit constraint, where capital plays the role of collateral, and of taste for domestic public debt, there is non-substitutability between the different assets: productive capital, public debt and an international asset. Finally, in accordance with Minea and Villieu (2013) or Morimoto et al. (2017), we assume that public debt follows a stability constraint.

We discuss the effect of public debt on growth and whether a lower debtoutput ratio may be stabilizing, by ruling out equilibria multiplicity. Our results are quite different from those provided by the previous literature. When the debt-output ratio is high enough, we show that there is a unique BGP which is locally indeterminate. This striking conclusion is explained by the possibility to borrow on the international market and the existence

\footnotetext{
${ }^{2}$ Such a borrowing constraint is especially relevant in a small open economy since it allows to keep the economy sufficiently small with respect to the rest of the world.
} 
of an investment multiplier. On the contrary, when the debt-output ratio is low enough, two BGPs may coexist: there is also a BGP with a lower growth rate which is saddle-point stable, implying global indeterminacy and coordination problems. These BGPs can be both characterized by a primary deficit, or the lower one can be characterized by a primary surplus. In this last configuration, where the interest rate is above the growth rate, household taste for domestic public debt plays a key role. When it is high enough, the proportion of domestic public debt is too big to satisfy the household budget constraint when growth is low, which rules out the existence of the BGP with the lowest growth rate. However, taste for domestic public debt does not modify the stability properties of the BGPs. This means that, while a high share of public debt held by domestic households does not affect the local indeterminacy of the BGP with the highest growth rate, it may eliminate the multiplicity of BGPs, i.e. it rules out global indeterminacy.

Our results have also clear policy implications. A lower debt-output ratio does not stabilize endogenous fluctuations. Indeed, the BGP with the highest growth rate is locally indeterminate whatever the level of the debt-output ratio, while a sufficiently low debt-output ratio may promote the multiplicity of BGPs, i.e. may be a source of global indeterminacy. This conclusion is completely different from the one obtained in a small open economy with perfectly substitutable assets in which a sufficiently low public debt stabilizes expectation-driven fluctuations (Morimoto et al. (2017)). In a closed economy with perfectly substitutable assets, and a log-linear utility in consumption as in our paper, multiplicity of equilibria is also ruled out for any level of the debt-output ratio (Minea and Villieu (2013)). ${ }^{3}$

The source of multiplicity of equilibria in our model is related to two key features of our framework: $(i)$ the inflow of international assets and $(i i)$ the existence of non substitutable assets due to a credit constraint with collateral. Indeed, in a closed economy with perfectly substitutable assets, expectations of higher public expenditures cannot be self-fulfilling. To finance higher public expenditures, a larger debt emission is indeed required, which crowds

\footnotetext{
${ }^{3}$ In Chéron et al. (2019), it is however shown that, in a closed economy, local and global indeterminacies may occur if the elasticity of intertemporal substitution is sufficiently larger than 1.
} 
out private investment having a negative impact on future income. It then prevents the existence of expectation-driven fluctuations. In contrast, in our framework, as a small open economy can import international funds, such a crowding-out effect is no longer relevant. Therefore, a higher public spending is now compatible with an increase of productive investment. The resulting effect on growth is magnified by the collateral role of capital which generates an investment multiplier. Higher investment and growth sustain an expected increase of public spending, which is not possible when assets are perfectly substitutable (Morimoto et al. (2017)).

Given our results on local and global indeterminacy, we finally provide a simple numerical illustration in order to check whether the preference of households for domestic bonds can explain the heterogeneity of experiences across some OECD countries using specific calibrations based on empirical evidence. We especially illustrate that while both Greece and Japan are characterized by high debt-output ratios, they do not feature the same dynamics. Indeed, Greece appears to be characterized by a preference for domestic bonds which allows the multiplicity of BGPs, whereas it is not the case for Japan. This may explain why Japanese debt is more stable than the Greek one.

This paper is organized as follows. In Section 2, we present the model. In Section 3, we analyze the existence and the multiplicity of BGPs. We also discuss the features of these BGPs and analyze comparative statics. In Section 4, we analyze the stability of BGPs. We provide a numerical illustration of our results in Section 5. We conclude in Section 6, while most technical details are relegated to an Appendix.

\section{The model}

We consider a continuous time small open economy with three types of agents, a large number of identical competitive firms, a constant population of identical infinitely lived households, and a government. 


\subsection{Production}

We consider a perfectly competitive economy where the final output $y$ is produced using capital $k$ and labor supplied in one unit. As in Barro (1990), the production also benefits from an externality due to public spending $G$, and is given by $y=k^{s} G^{1-s}$.

The rental rate of capital $r_{k}(t)$ and the wage rate $w(t)$ then satisfy:

$$
\begin{aligned}
r_{k}(t) & =s x(t)^{1-s} \\
w(t) & =(1-s) x(t)^{1-s} k(t)
\end{aligned}
$$

where $x \equiv G / k$.

\subsection{Households' behavior}

The infinitely-lived household derives utility from consumption $c(t)$ and from holding domestic public debt $B_{h}(t)$. Households can also save through capital $k(t)$ and can buy or sell the international asset $d(t)$ from/to foreigners. The two financial assets are freely traded on international markets, whereas capital used in production is not mobile.

The intertemporal maximization program of a representative agent is given by:

$$
\begin{aligned}
\max _{c(t), B_{h}(t), k(t), d(t)} & \int_{t=0}^{+\infty} e^{-\rho t}\left[\ln c(t)+\beta \ln B_{h}(t)\right] d t \\
\text { s.t. } c(t)+\dot{k}(t)+\dot{d}(t)+\dot{B}_{h}(t) & =(1-\tau)\left(r_{k}(t) k(t)+w(t)\right)+r d(t)+r B_{h}(t) \\
r d(t) & \geq-\theta(1-\tau) r_{k}(t) k(t)
\end{aligned}
$$

where $\rho>0$ is the discount rate and $\beta \geqslant 0$ is a parameter that measures the preference for domestic bonds of domestic residents. The tax rate on income $\tau \in[0,1)$ and the international interest rate $r>0$ are assumed to be constant. As in Fahri and Tirole (2012) or Hirano and Yanagawa (2017), the parameter $\theta \in(0,1)$ is a measure of credit market imperfection when the borrowing constraint (4) is binding. The larger $\theta$ is, the less significant the degree of this imperfection.

Our aim in this paper is to study portfolio decisions based on three assets, i.e. domestic public debt, physical capital and foreign assets, that are not perfectly substitutable. However, since there is only one dynamical equation 
corresponding to the budget constraint of the representative household, there are not enough equations to solve the intertemporal optimization problem using Hamiltonian techniques. We need to use instead the standard method of calculus of variations based on the consideration of the Euler equation. Let us then introduce the following Lagrangian:

$$
\begin{aligned}
\mathcal{L}= & e^{-\rho t}\left[\ln \left((1-\tau)\left(r_{k}(t) k(t)+w(t)\right)+r d(t)+r B_{h}(t)-\dot{k}(t)-\dot{d}(t)-\dot{B}_{h}(t)\right)\right. \\
& \left.+\beta \ln B_{h}(t)\right]+\lambda(t)\left(r d(t)+\theta(1-\tau) r_{k}(t) k(t)\right)
\end{aligned}
$$

with $\lambda(t) \geqslant 0$ the Lagrange multiplier associated to the borrowing constraint. The first order conditions are derived from the Euler equation $\frac{\partial \mathcal{L}}{\partial \omega}=\frac{d}{d t} \frac{\partial \mathcal{L}}{\partial \dot{\omega}}$, with $\omega=\left\{k, d, B_{h}\right\}$ :

$$
\begin{aligned}
\frac{e^{-\rho t}(1-\tau) r_{k}(t)}{c(t)}+\lambda(t)(1-\tau) \theta r_{k}(t) & =\frac{e^{-\rho t}}{c(t)}\left(\rho+\frac{\dot{c}(t)}{c(t)}\right) \\
\left(\frac{e^{-\rho t}}{c(t)}+\lambda(t)\right) r & =\frac{e^{-\rho t}}{c(t)}\left(\rho+\frac{\dot{c}(t)}{c(t)}\right) \\
e^{-\rho t}\left(\frac{r}{c(t)}+\frac{\beta}{B_{h}(t)}\right) & =\frac{e^{-\rho t}}{c(t)}\left(\rho+\frac{\dot{c}(t)}{c(t)}\right)
\end{aligned}
$$

Any solution needs also to satisfy the transversality conditions:

$$
\lim _{t \rightarrow+\infty} e^{-\rho t} \omega(t) / c(t)=0, \quad \text { with } \omega(t)=\left\{k(t), d(t), B_{h}(t)\right\}
$$

Using (5) and (6), the Lagrange multiplier is given by:

$$
\lambda(t)=\frac{e^{-\rho t}}{c(t)}\left(\frac{(1-\tau) r_{k}(t)-r}{r-\theta(1-\tau) r_{k}(t)}\right)
$$

and we obviously get $\lambda(t)>0$ if and only if:

$$
(1-\tau) r_{k}(t)>r>\theta(1-\tau) r_{k}(t)
$$

In the following, we focus on configurations where the credit constraint (4) is binding, i.e. condition (10) is satisfied. Substituting (9) in (5), we obtain the consumption growth rate:

$$
\frac{\dot{c}(t)}{c(t)}=\frac{(1-\tau) r_{k}(t)(1-\theta)}{1-\theta(1-\tau) r_{k}(t) / r}-\rho
$$

If the different assets were perfect substitutes, the growth rate of consumption would be $r-\rho$. In our model, as borrowing on the international 
market requires collateral and should be reimbursed, the expected return of capital is

$$
\frac{(1-\tau) r_{k}(t)(1-\theta)}{1-\theta(1-\tau) r_{k}(t) / r}
$$

Indeed, the marginal benefit of investing one unit of capital becomes (1 $\tau) r_{k}(t)(1-\theta)$, whereas the expected cost of investing one unit of capital is reduced to $1-\theta(1-\tau) r_{k}(t) / r$.

Using (5), (7) and (9), we define the arbitrage between capital and the public asset that allows to determine the level of public debt held by residents:

$$
r+\frac{\beta c(t)}{B_{h}(t)}=\frac{(1-\tau) r_{k}(t)(1-\theta)}{1-\theta(1-\tau) r_{k}(t) / r}
$$

One of the key ingredients of our model is the coexistence of three assets that, a priori, are not perfect substitutes. Foreigners are indifferent between holding the international asset and domestic public debt because they have the same international return $r$. However, for residents, this is not the case, since borrowing on the international market requires collateral and residents enjoy holding domestic public debt. Both mechanisms increase the marginal utility of holding these assets.

\subsection{Government}

The government finances public spending $G$ by income taxation $\tau\left(r_{k} k+w\right)$ and debt emission $B$. Debt is explicitly composed by public bonds held by foreigners $B_{f}$ and by residents $B_{h}$, i.e. $B=B_{f}+B_{h}$. The government budget constraint writes:

$$
\dot{B}(t)=G(t)+r B(t)-\tau\left(w(t)+r_{k}(t) k(t)\right)
$$

Public debt also follows a stability constraint. Let $b \equiv B / y$ the ratio of debt over GDP. According to Minea and Villieu (2013) or Morimoto at al. (2017), the government aims to converge to a certain level of the ratio of debt over GDP, namely $\bar{b}$, which may be seen as a policy parameter. This means that:

$$
\frac{\dot{b}(t)}{b(t)}=-\phi\left(1-\frac{\bar{b}}{b(t)}\right), \text { with } \phi>0
$$

The parameter $\phi$ is obviously the adjustment coefficient of debt with respect to the target. It is a policy parameter. 


\subsection{Intertemporal equilibrium}

Using the equilibrium prices (1) and (2), the constraint on public debt (15) and $G / y=x^{s}$, equation (14) gives the growth rate of production:

$$
\frac{\dot{y}(t)}{y(t)}=\frac{x(t)^{s}}{b(t)}+r-\frac{\tau}{b(t)}+\phi\left(1-\frac{\bar{b}}{b(t)}\right)
$$

and the growth rate of consumption (11) can be rewritten:

$$
\Gamma(x(t)) \equiv \frac{\dot{c}(t)}{c(t)}=\frac{(1-\tau) s x(t)^{1-s}(1-\theta)}{1-\theta(1-\tau) s x(t)^{1-s} / r}-\rho
$$

This equation shows that the growth rate strongly increases with $x$. Because of the binding credit constraint (4), capital also plays the role of collateral, introducing a leverage effect that increases productive investment. This creates an investment multiplier, which explains that the growth rate strongly reacts to public spending over GDP, a measure of the productivity of capital. It is also interesting to note that an increase of $\theta$ which relaxes the credit constraint, increases the net return of capital, which as expected, fosters growth. Of course, a lower $r$ has the same effect since it facilitates borrowing on the international market.

A binding credit constraint (4) means that $d=-\theta(1-\tau) s y / r$. This also implies that $\dot{d} / d=\dot{y} / y$. Using the arbitrage condition (13), we obtain an expression for the public debt held by residents:

$$
B_{h}(t)=\frac{\beta c(t)}{r}\left(\frac{r-\theta(1-\tau) s x(t)^{1-s}}{(1-\tau) s x(t)^{1-s}-r}\right)
$$

Obviously, if $\beta=0$, we observe that there is no domestic holding of the public debt. ${ }^{4}$ The assumption of preferences for domestic debt is therefore crucial to consider a portfolio containing the three imperfectly substitutable assets and to be in line with the fact that in most OECD countries a significant but variable part of public debt is hold by residents. Note indeed that everything else equal, $B_{h}(t)$ is increasing with the parameter $\beta$ measuring the preference for domestic bonds. We get from (18):

$$
\frac{\dot{B}_{h}(t)}{B_{h}(t)}=\frac{\dot{c}(t)}{c(t)}-\left(\frac{r(1-\theta)(1-\tau) s x(t)^{1-s}}{\left[r-\theta(1-\tau) s x(t)^{1-s}\right]\left[(1-\tau) s x(t)^{1-s}-r\right]}\right) \frac{\dot{x}(t)}{x(t)}
$$

\footnotetext{
${ }^{4}$ Actually, to prove such a result when $\beta=0$, we need to introduce in the Lagrangian an additional multiplier $\mu(t)$ associated to the positivity constraint $B_{h}(t) \geq 0$. Then we easily show that when the credit constraint (4) is binding, we have $\lambda(t) r=\mu(t)>0$ and thus $B_{h}(t)=0$. In such a case indeed domestic public bonds are always dominated by the international asset $d(t)$ through the credit constraint.
} 
Using (3), we also derive the growth rate of capital:

$$
\begin{aligned}
\frac{\dot{k}(t)}{k(t)} & =(1-\tau)(1-\theta s) x(t)^{1-s}+\frac{c(t)}{k(t)}\left[\beta \frac{\theta(1-\tau) s x(t)^{1-s}-r}{r-(1-\tau) s x(t)^{1-s}}-1\right] \\
& -\frac{B_{h}(t)}{k(t)} \frac{\dot{B}_{h}(t)}{B_{h}(t)}+\frac{\theta(1-\tau) s}{r} x(t)^{1-s} \frac{\dot{y}(t)}{y(t)}
\end{aligned}
$$

Let us introduce the variable $v \equiv c / y$. Using (16) and (17), we easily get:

$$
\begin{aligned}
\frac{\dot{v}(t)}{v(t)} & =\frac{r(1-\tau) s x(t)^{1-s}(1-\theta)}{r-\theta(1-\tau) s x(t)^{1-s}}-\rho-\frac{x(t)^{s}}{b(t)}-r+\frac{\tau}{b(t)}-\phi\left(1-\frac{\bar{b}}{b(t)}\right) \\
& \equiv V(b(t), x(t))
\end{aligned}
$$

Note that $x=G / k=(y / k)^{\frac{1}{1-s}}$. Using now (16), (17), (19) and (20), we determine $\dot{x} / x$ as follows:

$$
\begin{aligned}
\frac{\dot{x}(t)}{x(t)} & =\frac{\left(\frac{r-\theta(1-\tau) s x(t)^{1-s}}{r}\right)\left[\frac{x(t)^{s}}{b(t)}+r-\frac{\tau}{b(t)}+\phi\left(1-\frac{\bar{b}}{b(t)}\right)\right]-(1-\tau)(1-\theta s) x(t)^{1-s}}{(1-s)\left[1+\beta v(t) x(t)^{1-s} \frac{(1-\theta)(1-\tau) s(t) 1-s}{\left[(1-\tau) s x(t)^{1-s}-r\right]^{2}}\right]} \\
& -\frac{\left.r v(t) x(t)^{1-s}\left\{\left(\frac{\beta}{r} \frac{r-\theta(1-\tau) s x(t) 1^{1-s}}{(1-\tau) s x(t)^{1-s}-r}\right)\left[1-\frac{1}{r}\left(\frac{r(1-\theta)(1-\tau) s x(t)}{r-\theta(1-\tau) s x(t)}\right)^{1-s}-\rho\right)\right]-\frac{1}{r}\right\}}{(1-s)\left[1+\beta v(t) x(t)^{1-s} \frac{(1-\theta)(1-\tau) s(t) 1-s}{\left[(1-\tau) s x(t)^{1-s}-r\right]^{2}}\right]} \\
& \equiv X(b(t), v(t), x(t))
\end{aligned}
$$

Equations (15), (21) and (22) determine a three-dimensional dynamic system involving the variables $(b(t), v(t), x(t))$ that governs the dynamics of our model. We further note that only one variable, namely $b(t)$, is predetermined while $v(t)$ and $x(t)$ are forward variables. Of course, any equilibrium needs also to satisfy the transversality conditions (8).

\section{Analysis of the balanced growth path (BGP)}

A BGP is a steady state of the dynamic system (15), (21) and (22), i.e. is a stationary solution $(b, v, x)$ solving $\dot{b}(t)=0, \dot{v}(t)=0$ and $\dot{x}(t)=0$. Such a solution satisfies

$$
\frac{\dot{c}(t)}{c(t)}=\frac{\dot{k}(t)}{k(t)}=\frac{\dot{y}(t)}{y(t)}=\frac{\dot{B_{h}}(t)}{B_{h}(t)} \equiv \Gamma(x)
$$

By direct inspection of (8), the transversality conditions are always satisfied along a BGP. 
Using (15), we see that, along a BGP, we always have $b=\bar{b}$. Then, $\dot{v}(t)=0$ is satisfied for a value of $x$ solving:

$$
\Gamma(x)=H(x)
$$

with:

$$
\begin{aligned}
\Gamma(x) & \equiv \frac{(1-\tau) s x^{1-s}(1-\theta)}{1-\theta(1-\tau) s x^{1-s} / r}-\rho \\
H(x) & \equiv \frac{x^{s}}{\bar{b}}+r-\frac{\tau}{\bar{b}}
\end{aligned}
$$

It is worth noticing that any solution $x$ of equation (23) does not depend on $\beta$. In fact, the only variables that react to $\beta$ are $v=c / y$ and $b_{h}=B_{h} / y$.

Given the solution $x$, equation (22) with $\dot{x}(t)=0$ gives a unique solution $v$ such that:

$$
v=\frac{(1-\tau)(1-s) x^{1-s}+\left[r-\theta(1-\tau) s x^{1-s}\right] \rho / r}{x^{1-s}\left[\left(\frac{\beta}{r} \frac{r-\theta(1-\tau) s x^{1-s}}{(1-\tau) s x^{1-s}-r}\right) \frac{x^{s}-\tau}{\bar{b}}+1\right]}
$$

which depends on $\beta$. An important property is that $v>0$ for any $\beta \geq 0$ only if the solution $x$ is such that $x^{s}-\tau \geq 0$, while there exists a $\bar{\beta}>0$ such that when the solution $x$ is characterized by $x^{s}-\tau<0, v>0$ if and only if $\beta \in(0, \bar{\beta})$. As we will discuss below, the sign of $x^{s}-\tau$ depends on whether $x$ is characterized by a primary surplus or a primary deficit. This will have some important consequences on the existence and multiplicity of steady states.

\subsection{Uniqueness versus multiplicity of BGP}

Let us study the existence and uniqueness versus multiplicity of BGP. Recall that the credit constraint (4) is binding. Using (1) and (10), this means that $x_{b}<x<x_{a}$, with:

$$
x_{a} \equiv\left(\frac{r}{(1-\tau) s \theta}\right)^{\frac{1}{1-s}} \text { and } x_{b} \equiv\left(\frac{r}{(1-\tau) s}\right)^{\frac{1}{1-s}}
$$

We assume:

Assumption 1. $r>\rho$ and $\theta \geq s /(2-s)$. 
The first part of Assumption 1 ensures that the growth rate is positive whatever the value of $\theta$ (see equation (17)) while the second part allows to simplify the analysis, ensuring that $\Gamma(x)$ is a convex function. ${ }^{5}$

Beside the analysis of existence and uniqueness of the steady state, we need also to determine whether the steady state is characterized by a primary surplus or rather a primary deficit. A primary surplus (deficit) is obtained if and only if $\tau y-G>(<) 0$. It is therefore immediate to derive that a stationary solution $x$ features a primary surplus if $x^{s}-\tau<0$, i.e. $x<\tau^{1 / s} \equiv$ $x_{0}$, and a primary deficit if $x^{s}-\tau>0$, i.e. $x>x_{0}$. For further references, $x_{b}$ satisfies a primary deficit if and only if $r>r_{b}$, with:

$$
r_{b} \equiv \tau^{\frac{1-s}{s}}(1-\tau) s
$$

while $x_{a}$ satisfies a primary deficit if and only if $r>r_{a}$, with

$$
r_{a} \equiv \tau^{\frac{1-s}{s}}(1-\tau) s \theta=\theta r_{b}
$$

In the following Proposition, we show that there is a unique BGP if the debt-output ratio is sufficiently high, as illustrated in Figure 1, and that, depending on the value of the interest rate $r$, it is characterized by a primary deficit or surplus:

Proposition 1. Under Assumption 1, there exist $\bar{\beta} \in(0,+\infty)$ and $r_{0} \in$ $\left(r_{a}, r_{b}\right)$ such that if $\bar{b}>\widehat{b}$, with

$$
\widehat{b} \equiv \frac{\tau-\left(\frac{r}{(1-\tau) s}\right)^{\frac{s}{1-s}}}{\rho}
$$

there is a unique stationary solution $x \in\left(x_{b}, x_{a}\right)$ of (23) in the following cases:

i) when $r>r_{0}$ and for any $\beta \geq 0$, with $x$ characterized by a primary deficit, i.e. such that $x^{s}-\tau>0$,

ii) when $r<r_{0}$ and $\beta \in[0, \bar{\beta})$, with $x$ characterized by a primary surplus, i.e. such that $x^{s}-\tau<0$.

Proof. See Appendix 7.1.

\footnotetext{
${ }^{5}$ All our results on existence, uniqueness and multiplicity of steady states could be obtained even under $\theta<s /(2-s)$ but at the cost of cumbersome technical details.
} 


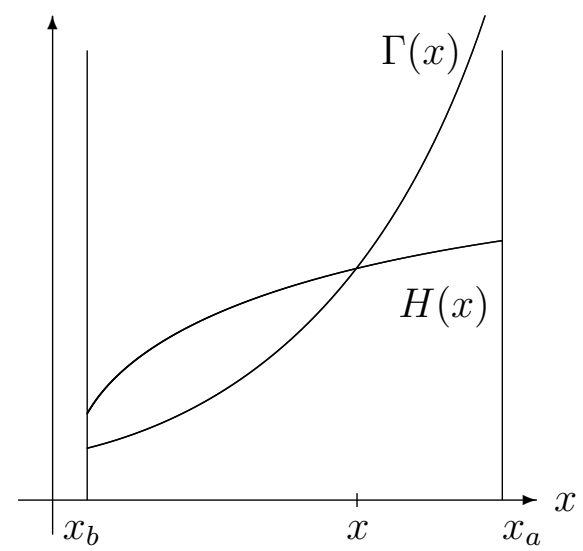

Figure 1: Uniqueness of BGP

A sufficiently high interest rate $r>r_{0}$ pushes down growth. To sustain the reimbursement of the high level of public debt, a sufficient high level of growth is however needed, which means that public spending should be high enough. This explains that there is a primary deficit. Of course, when $r<r_{0}$, we have exactly the opposite situation. It is important to note that when $r<r_{0}$ and $\beta>\bar{\beta}$, there does not exist any admissible steady state since the associated consumption level $v$ becomes negative. As the amount of debt is large, $\bar{b}>\widehat{b}$, the return of debt $r$ is larger than growth $\Gamma$, and, as households have a strong taste for their domestic debt, they hold a too large amount of domestic public assets $B_{h}$ to be sustained by their budget constraint.

To understand why uniqueness occurs under a large debt-output ratio, ${ }^{6}$ we rewrite the government budget constraint (23) as $\Gamma(x) \bar{b}=G / y-\tau+r \bar{b}$. For a too low $x$, growth is not sufficient to allow the repayment of a high level of debt. Hence, a large debt-output ratio is not compatible with the government budget constraint and cannot be sustained, so that a too low steady state cannot exist.

Let us focus now on the case where $\bar{b}$ is low enough, i.e. $\bar{b}<\widehat{b},{ }^{7}$ depicted in Figure 2. We can show that two BGPs may now coexist.

\footnotetext{
${ }^{6}$ As suggested by Figures 1 and 2, uniqueness corresponds to a configuration where a unique "large" steady state $x$ occurs while a lower one is outside of the admissible set $\left(x_{b}, x_{a}\right)$ as it is unsustainable.

${ }^{7}$ Note that $\widehat{b}>0$ requires $r<r_{b}$.
} 
Proposition 2. Under Assumption 1, let $\widetilde{r} \equiv \tau^{\frac{1-s}{s}}(1-\tau) s \widetilde{\theta}$ and

$$
\widetilde{b} \equiv \frac{\left(\frac{r}{(1-\tau) s \tilde{\theta}}\right)^{\frac{s}{1-s}}-\tau}{r \frac{1-\widetilde{\theta}}{\tilde{\theta}-\theta}-\rho}
$$

For given $(\bar{b}, \theta, r)$, there exist $\bar{\beta}>0, \bar{\rho}>0, \tilde{\theta} \in(\theta, 1), \underline{r} \in\left(\widetilde{r}, r_{b}\right)$ and $\bar{b}^{\text {max }} \leq \min \{\widetilde{b}, \widehat{b}\}$ such that:

1. If $\rho \in(0, \bar{\rho})$ and $\bar{b}<\bar{b}^{\text {max }}$, there are two stationary solutions $x_{1}, x_{2} \in$ $\left(x_{b}, x_{a}\right)$ of (23) in the following cases:

i) when $r \in\left(\underline{r}, r_{0}\right)$ and for any $\beta \geq 0$, with $\left(x_{0}<\right) x_{1}<x_{2}$ both characterized by a primary deficit,

ii) when $r \in\left(r_{0}, r_{b}\right)$ and $\beta \in[0, \bar{\beta})$, with $x_{1}\left(<x_{0}\right)$ characterized by a primary surplus and $x_{2}\left(>x_{0}\right)$ characterized by a primary deficit.

2. If $\rho \in(0, \bar{\rho}), \bar{b}<\bar{b}^{\max }, r \in\left(r_{0}, r_{b}\right)$ and $\beta>\bar{\beta}, x_{2}\left(>x_{0}\right)$ is the unique steady state and is characterized by a primary deficit.

Proof. See Appendix 7.2.

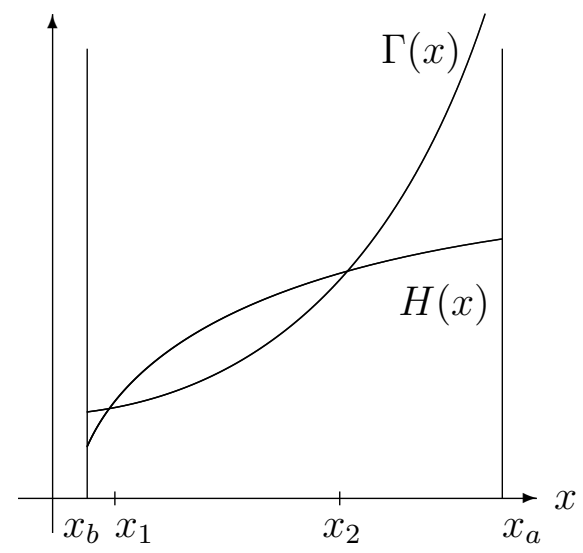

Figure 2: Multiplicity of BGPs

From Propositions 1 and 2, we conclude that multiplicity of BGPs is only possible if the debt-output ratio is sufficiently low and the interest rate is sufficiently high, i.e. $r \in\left(\underline{r}, r_{b}\right)$. However, if the interest rate is in the upper range of this interval, i.e. $r \in\left(r_{0}, r_{b}\right)$, the multiplicity also requires a low 
enough taste for domestic public debt, $\beta \in[0, \bar{\beta})$. The lowest steady state characterized by a primary surplus becomes indeed inadmissible when the taste for domestic debt $\beta$ is too large. Of course, a primary surplus can only occur at a low steady state under a relatively high interest rate to have a growth rate $\Gamma(x)$ smaller than $r$. In this case, a primary surplus $\tau>x^{s}$ is indeed required to sustain the government budget.

To understand now why multiplicity can occur under a low enough debtoutput ratio, consider again the government budget constraint (23) rewritten as $\Gamma(x) \bar{b}=G / y-\tau+r \bar{b}$. If the debt-output ratio is low enough, the government budget constraint is sustainable even with a low growth rate, which explains the existence of the low steady state $\left(x_{1}\right)$. In contrast, at a high steady state $\left(x_{2}\right)$, the growth rate is high enough to sustain the government budget whatever the level of debt. Given a sufficiently low level of public debt, the multiplicity of BGPs is explained by the coexistence of two key mechanisms: $(i)$ the inflow of international assets and $(i i)$ the existence of an investment multiplier due to the credit constraint with collateral.

In a closed economy with perfectly substitutable assets (public debt and capital), multiplicity of BGPs is ruled out under a log linear utility function in consumption, as shown by Minea and Villieu (2013). ${ }^{8}$ Indeed, if agents expect an increase of public expenditures, this will induce a higher future income. To finance this increase in public spending, a larger debt emission is required, which crowds out private investment having a negative impact on future income. Then, expectations may not be self-fulfilling, which explains uniqueness.

In contrast, in our framework, as a small open economy can import international funds, such a crowding out effect is no longer relevant. Therefore, a higher public spending is now compatible with an increase of productive investment. The resulting effect on growth is magnified by the collateral role of capital which generates an investment multiplier. In this case, an expected increase of public spending is self-fulfilling because of higher future income and growth, which sustain a long run equilibrium with larger public spending.

\footnotetext{
${ }^{8}$ As shown in Chéron et al. (2019), mulitplicity can be restored in a closed economy if the elasticity of intertemporal substitution in consumption is sufficiently larger than one.
} 
Notice that Morimoto et al. (2017) also consider a small open economy but obtain a unique BGP because, contrary to our formulation, all assets are perfectly substitutable. Indeed, in their case, the growth rate $\Gamma(x)$ becomes equal to the constant level $r-\rho$ and there is a unique level of public spending per GDP $\left(x^{s}\right)$ that sustains the government budget in the long run. There is no longer any investment multiplier and, thus, any increase of productive investment is not sufficient to sustain the increase of government spending. Therefore, expectations cannot be self-fulfilling.

\subsubsection{The effect of preferences for domestic public debt}

The parameter $\beta$ measuring the taste for domestic public debt is crucial to ensure, in the portfolio of domestic households, the coexistence of three assets that, a priori, are not perfect substitutes. Recalling that $x, \Gamma, k / y$, $d / y=-\theta(1-\tau) s / r$ and $b$ are not affected by the preference parameter $\beta$, we easily derive from (18) and (26) that following an increase of $\beta$, the holding of public debt by residents $b_{h}$ increases, while consumption $c / y$ increases (decreases) if and only if the steady state under analysis is characterized by a primary surplus (deficit). We can also compute the share of public debt hold by residents as follows:

$$
\frac{B_{h}}{B}=\frac{\beta v}{r \bar{b}}\left(\frac{r-\theta(1-\tau) s x^{1-s}}{(1-\tau) s x^{1-s}-r}\right)
$$

with $v$ as given by (26). When evaluated along a steady state $x$ characterized by a primary deficit, this ratio is an increasing function of $\beta$.

To understand this effect on consumption over GDP, we look at the household budget constraint at a BGP:

$$
\frac{c}{y}+\Gamma\left(\frac{k}{y}+\frac{d}{y}\right)+(\Gamma-r) b_{h}=(1-\tau)+r \frac{d}{y}
$$

where all the variables, with the exception of $c / y$ and $b_{h}$, are invariant with respect to $\beta$. Therefore, following an increase of $b_{h}$, the ratio of consumption over GDP increases if and only if the marginal benefit of holding more debt $r$ is larger than its marginal cost $\Gamma$, i.e. the associated steady state is characterized by a primary surplus. However, when both $\beta$ is sufficiently high and the return of debt $r$ is larger than growth $\Gamma$, households would like to hold a too high level of domestic debt $b_{h}=B_{h} / y$ to be sustained by their budget constraint. This explains case 2 of Proposition 2 where the steady 
state $x_{1}$ characterized by a primary surplus, i.e. $r>\Gamma$, no longer exists if $\beta$ is too large.

This taste for domestic public debt also has some implications on the welfare $W$ evaluated at a BGP. As shown in Appendix 7.3, $W$ is equal to:

$$
W=\frac{1}{\rho^{2}}[(1+\beta) \Gamma(x)+\rho((1+\beta) \ln c(0)+\beta \ln \widetilde{B}(x))]
$$

where

$$
\begin{aligned}
c(0) & =k(0) \frac{\left(1-\theta \frac{(1-\tau) s x^{1-s}}{r}\right) \rho+(1-\tau)(1-s) x^{1-s}}{1+(\Gamma(x)-r) \widetilde{B}(x)} \\
\widetilde{B}(x) & \equiv \frac{B_{h}(x)}{c}=\frac{\beta}{r}\left(\frac{r-\theta(1-\tau) s x^{1-s}}{(1-\tau) s x^{1-s}-r}\right)
\end{aligned}
$$

Considering that $\rho$ is low enough, the dominant effect goes through the growth rate $\Gamma(x)$. Since both consumption and domestic public debt raise at this rate, a higher $\beta$ reinforces this growth rate effect. In addition, since $\Gamma(x)$ is increasing in $x$, the welfare will be larger with a higher level of $x$. This means that when there is a multiplicity of steady states, they are Pareto ranked, the welfare associated to $x_{1}$ being lower than the one associated to $x_{2}$, and any policy which raises the value of $x$ is Pareto improving.

To complement our previous discussion, we also see that $\widetilde{B}(0)=$ $B_{h}(0) / c(0)$ increases with $\beta$, while $c(0)$ increases with $\beta$ if and only if $r>\Gamma(x)$. In such a case, a higher taste for domestic public debt $\beta$ means more welfare, not only because it reinforces the effect of growth, but also because it raises the initial values of consumption and domestic holding of public debt.

\subsubsection{The role of the international credit market}

We finally briefly study how modifications of the credit market features affect the long run BGPs. We focus on the configurations with two steady states, as the comparative statics when there is one steady state are identical to the ones obtained with the highest steady state. Note that from Figure 2, we observe that $\Gamma(x) \bar{b}<G / y-\tau+r \bar{b}$ for all $x$ between $x_{1}$ and $x_{2}$. This means that in this region, growth is not high enough to sustain the sum of the primary deficit and debt reimbursement. Therefore, the question will be to know whether this region enlarges or reduces when the credit market features change. 
We study first the effects of relaxing the credit constraint through an increase of $\theta$ the degree of pledgeability. When $\theta$ increases, the access to external funds is facilitated, but it is still constrained by capital revenues. Through the credit constraint (4), the collateral role of capital is reinforced, amplifying the usual leverage effect that increases productive investment. This mechanism strengthens the investment multiplier increasing growth. For a given level of $x$, this ensures more public debt emission, i.e. the curve $\Gamma(x)$ moves upward in Figure 3.

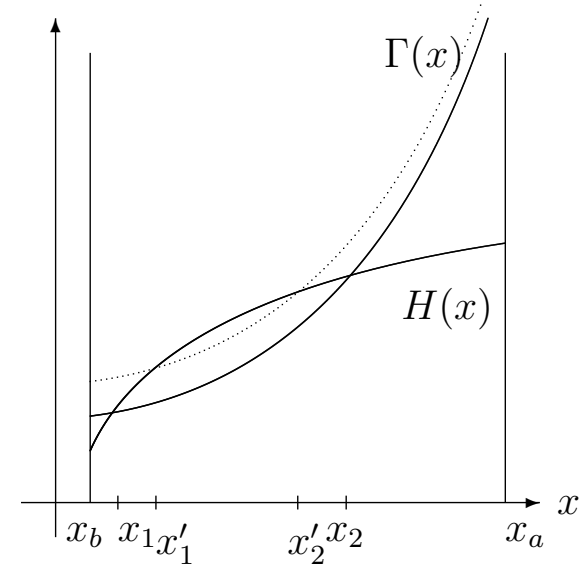

Figure 3: The impact of an increase of $\theta$

This reduces the region where growth is not sufficient to sustain the sum of the primary deficit and debt reimbursement. Therefore, $x_{2}$ and its associated growth rate $\Gamma\left(x_{2}\right)$ decrease, and $x_{1}$ and the corresponding growth rate $\Gamma\left(x_{1}\right)$ increase.

We now analyze the effects of decreasing the cost of international funds on steady state equilibria. Following a decrease of the international interest rate $r$, the interest burden is reduced for any level of $x$, which shifts the $H(x)$ curve downward. At the same time, the growth rate increases. Indeed, the cost of external debt becoming lower, we observe a higher inflow of international funds which relaxes the credit constraint increasing the collateral value of capital. Hence, residents invest more in productive capital, which fosters growth, shifting the $\Gamma(x)$ curve upward. Consequently, as shown in Figure 4, the region where growth is not enough to sustain the sum of the primary deficit and debt reimbursement, i.e. $\Gamma(x) \bar{b}<G / y-\tau+r \bar{b}$, 
is reduced. Thus, $x_{2}$ and its associated growth rate $\Gamma\left(x_{2}\right)$ decrease, and $x_{1}$ and the corresponding growth rate $\Gamma\left(x_{1}\right)$ increase in order to ensure that the government budget constraint is satisfied at both BGPs.

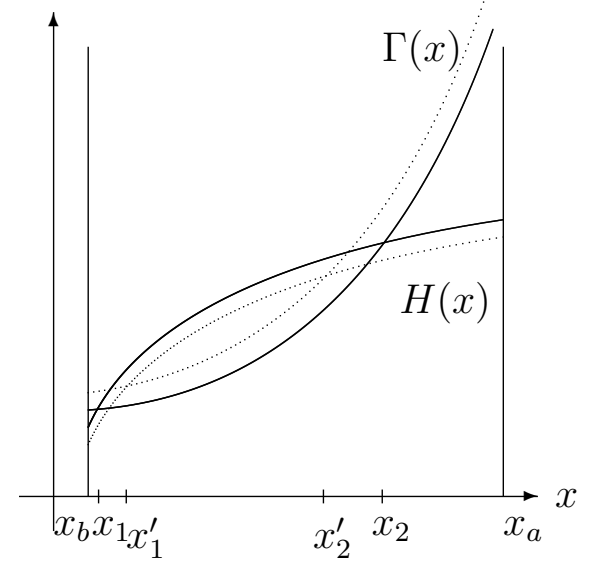

Figure 4: The impact of an increase of $r$

\subsection{The effect of an increase of the targeted debt-output ratio}

To contribute to the debate initiated by Reinhart and Rogoff (2010) on the relationship between growth and public debt, we now discuss the long run effect of a variation of the debt-output ratio $\bar{b}$. We have already shown that the amount of debt has a strong impact on the uniqueness/multiplicity properties of the steady state. Indeed, when $\bar{b}$ is large enough, i.e. larger than a critical bound $\widehat{b}$, the steady state is unique, while two steady states arise when debt is low enough, i.e. $\bar{b}<b^{\max }$. This result immediately shows that the impact of debt on growth is not as obvious as discussed in the well-known contribution of Reinhart and Rogoff (2010) since the multiplicity issue is not considered in their paper. We prove here that a large debt ensures uniqueness while a low debt promotes multiplicity and thus potentially opens room for global indeterminacy and large fluctuations. Moreover, the following comparative statics results provide additional reasons to evaluate the impact of debt on growth with caution. 
Proposition 3. Under Assumption 1, the following results hold:

1. If the steady state $x$ is unique:

(a) when $\bar{b}>\widehat{b}, r<r_{0}$ and $\beta \in[0, \bar{\beta}), d x / d \bar{b}>0$,

(b) when $\bar{b}>\widehat{b}, r>r_{0}$ and $\beta \geq 0, d x / d \bar{b}<0$,

(c) when $\rho \in(0, \bar{\rho}), \bar{b}<\bar{b}^{\max }, r \in\left(r_{0}, r_{b}\right)$ and $\beta>\bar{\beta}$, $d x / d \bar{b}<0$.

2. If there exist two steady states $x_{1}<x_{2}$ :

(a) when $\rho \in(0, \bar{\rho}), \bar{b}<\bar{b}^{\max }, r \in\left(\underline{r}, r_{0}\right)$ and $\beta \geq 0, d x_{1} / d \bar{b}>0$ and $d x_{2} / d \bar{b}<0$,

(b) when $\rho \in(0, \bar{\rho}), \bar{b}<\bar{b}^{\text {max }}, r \in\left(r_{0}, r_{b}\right)$ and $\beta \in[0, \bar{\beta})$, $d x_{1} / d \bar{b}<0$ and $d x_{2} / d \bar{b}<0$.

Proof. See Appendix 7.4.

Proposition 3 clearly shows that the impact of debt on growth strongly depends on whether the steady state is unique or not, and on the properties of the steady state in terms of primary deficit or surplus.

To understand this result, let us consider the simplest case where all assets are perfect substitutes. In the absence of market imperfections, $\Gamma(x)$ is no longer a function of $x$, but is given by $r-\rho$. There is a unique BGP as depicted in the following Figure:

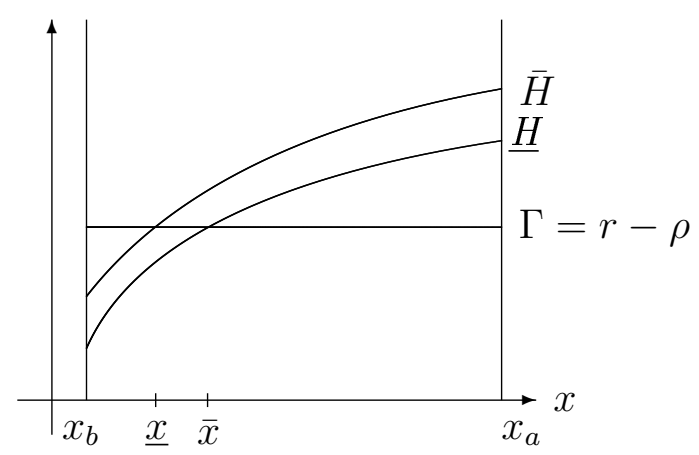

Figure 5: Multiplicity of BGPs 
When the steady state is characterized by a primary deficit, i.e. $G / y>\tau$, an increase of $\bar{b}$ generates a move from $\bar{H}$ to $\underline{H}$. Indeed, the difference between new debt emission and debt reimbursement increases. To ensure government budget constraint, public spending over GDP has to increase. Similarly, when the steady state is characterized by a primary surplus, i.e. $G / y<\tau$, an increase of $\bar{b}$ generates a move from $\underline{H}$ to $\bar{H}$, implying a decrease of public spending over GDP.

Let us come back to our model with market imperfections and an endogenous growth rate $\Gamma(x)$. In the case of multiple steady states, this mechanism explains what happens at the low BGP $x_{1}$, where the variations of $x$ are mainly determined by public spending over GDP. Therefore, when there is a primary deficit with a low interest rate, the growth rate increases, while it decreases when there is a primary surplus with a high interest rate.

The mechanism involved is quite different under uniqueness or at the high BGP in case of multiplicity. In both these situations, the investment multiplier plays a key role. Under multiplicity, as the higher steady state is always characterized by a primary deficit, $\Gamma$ is larger than $r$ in order to satisfy the government budget. Following an increase in the debt-output ratio $\bar{b}$, the curve $H$ shifts downwards, increasing the difference between new debt emission and debt reimbursement for a given level of $x$. To satisfy the government budget constraint, this excessive debt emission should be reduced, which happens through a lower growth rate.

When there is a unique steady state characterized by a primary deficit (cases 1.(b)-(c) of Proposition 3), the same mechanism as above holds. However, a unique BGP may alternatively be characterized by a primary surplus if the interest rate is low enough (case 1.(a) of Proposition 3). $\Gamma$ is lower than $r$ in order to satisfy the government budget and the mechanism is exactly the opposite. Following an increase in the debt-output ratio $\bar{b}$, the curve $H$ shifts upward, decreasing the difference between new debt emission and debt reimbursement for a given level of $x$. To satisfy the government budget constraint, this reduced debt emission should be dampened by a higher level of $x$ increasing growth.

As a direct implication of these results, we derive that the effect of debt on the growth rate depends on which equilibrium agents coordinate 
their expectations and on the properties of the equilibrium in terms of primary deficit or surplus. As uniqueness is obtained under a large enough debt/output ratio, the conclusions of Reinhart and Rogoff (2010) appear to require more examinations. In addition, since two BGPs may coexist under lower levels of debt, reducing public debt does not promote global determinacy and coordination of expectations on a unique equilibrium. In our open economy with borrowing constraint, we then obtain the opposite conclusion as the one obtained for a closed economy (see for instance Chéron et al. (2019)).

\section{Local stability analysis}

We study now the local stability properties of the BGPs to investigate if they may be locally indeterminate and expectation-driven fluctuations may occur. Let us consider the three-dimensional dynamic system as given by equations (15), (21) and (22) and that can be written as follows

$$
\begin{aligned}
\dot{b}(t) & =-\phi(b(t)-\bar{b}) \\
\dot{v}(t) & =V(b(t), x(t)) v(t) \\
\dot{x}(t) & =X(b(t), v(t), x(t)) x(t)
\end{aligned}
$$

The local stability properties of a given steady state are determined looking at the sign of the eigenvalues associated to the Jacobian matrix of system (33) evaluated at the steady state. The equation driving public debt being linear, one eigenvalue is necessarily negative and given by $\lambda_{1}=-\phi$. As our dynamical system is characterized by two forward variables, $v(t)$ and $x(t)$, we conclude that if the two remaining eigenvalues $\lambda_{2}$ and $\lambda_{3}$ have a positive real part, the steady state $\left(\bar{b}, v^{*}, x^{*}\right)$ is saddle-point stable. On the contrary, if one of these two eigenvalues has a negative real part, then the steady state $\left(\bar{b}, v^{*}, x^{*}\right)$ is locally indeterminate.

From the bound $\bar{\beta}$ and the conditions provided by Propositions 1-2, we prove:

Proposition 4. Under Assumption 1, let $\rho \in(0, \bar{\rho})$, and consider $b^{\text {max }} \leq \widehat{b}$ and $\underline{r} \in\left(r_{a}, r_{b}\right)$ as given in Proposition 2. Then the following results hold: 
1 - when $\bar{b}>\widehat{b}$ and $r>r_{0}$ with $\beta \geq 0$, or $r<r_{0}$ with $\beta \in[0, \bar{\beta})$, the unique stationary solution $x \in\left(x_{b}, x_{a}\right)$ is locally indeterminate;

2 - when $\rho \in(0, \bar{\rho}), \bar{b}<b^{\max }$ and $r \in\left(\underline{r}, r_{0}\right)$ with $\beta \geq 0$, or $r \in\left(r_{0}, r_{b}\right)$ with $\beta \in[0, \bar{\beta})$, the highest steady state $x_{2}^{*}$ is locally indeterminate and the lowest $x_{1}^{*}$ is saddle-point stable;

3 - when $\rho \in(0, \bar{\rho}), \bar{b}<b^{\max }$ and $r \in\left(r_{0}, r_{b}\right)$ with $\beta>\bar{\beta}$, the unique steady state $x_{2}^{*}$ is locally indeterminate.

Proof. See Appendix 7.5.

Proposition 4 shows first that when debt over GDP $\bar{b}$ is large enough, the unique steady state is necessarily locally indeterminate. The intuition for such a conclusion is quite simple. Starting from an equilibrium path, assume that agents expect a future increase of government spending and thus a future increase of output growth. Since a small open economy can import assets from the international market, the standard crowding out effect associated to an increase of public debt to finance government expenditure does not occur. At the same time, the existence of the collateral constraint implying imperfect substitutability among the three assets generates an investment multiplier that allows an even larger increase of output growth. As a result the large public debt can be sustained and the initial expectations are selffulfilling.

Proposition 4 also shows that when there are multiple steady states, the larger one is always locally indeterminate while the lower one is always saddlepoint stable. The intuition regarding the local indeterminacy of the highest steady state $x_{2}$ is identical to the one we just provide. Let us then focus on the intuition associated with the lowest steady state $x_{1}$ when $r \in\left(\underline{r}, r_{b}\right)$.

Starting from an equilibrium path, assume again that agents expect a future increase of government spending and thus a future increase of output growth. Since the interest rate is quite large, the cost of external debt is large and there are less asset inflows from abroad. Moreover, the credit constraint tightens, alleviating the collateral role of capital. As a result, households have less incentives to invest in productive capital, which limits the increase of the growth rate. At the same time, since public debt is fixed at a low level, it cannot be used to significantly increase government spending. It 
follows that the growth rate remains low and the initial expectations cannot be self-fulfilling, leading to a unique equilibrium path.

It is important to mention here that while the local stability property of each steady state is not strictly speaking affected by $\beta$, the taste for domestic public debt has a strong impact on the global indeterminacy properties of the model. Indeed, if $\beta$ is large enough, the lowest steady state is no longer admissible and global indeterminacy no longer holds. A large enough holding of public debt by domestic households therefore has a stabilizing impact even though the remaining unique steady state is still locally indeterminate. Large fluctuations of GDP associated to jumps between two steady states are therefore ruled out.

\section{A simple numerical illustration}

As explained in the introduction, the issue of debt sustainability that followed the last financial crisis appears to be quite heterogeneous across countries. While Greece has faced huge solvency problems after its debt-toGDP exceeded $150 \%$ in 2010, Japan does not seem to face similar difficulties with a debt-to-GDP ratio that has almost reached $250 \%$. Although debt sustainability is a complex question, particular empirical evidence provides a basis to understand this heterogeneity. Indeed on average in the Euro area and in the US, around $50 \%$ of public debt is held by non-residents, while in Japan and in UK only $4 \%$ and $31 \%$ respectively of the national public debt is held by non-residents. This means that most part of Japanese debt and a significant proportion of the UK debt are held by domestic institutions. Given our results on local and global indeterminacy, our aim is to provide some simple numerical illustration in order to check whether the parameter $\beta$ that measures the preference for domestic bonds of domestic residents can explain the observed heterogeneity across countries using specific calibrations based on empirical evidence.

The following table provides the fiscal pressure $\tau$, the share of capital income in GDP $s$, the share of gross debt in GDP $b,{ }^{9}$, the interest rate for

\footnotetext{
${ }^{9}$ The debt indicator is defined (in the Maastricht Treaty) as consolidated general government gross debt at nominal (face) value, outstanding at the end of the year in
} 
international borrowing $r$ and the share of debt held by residents $B_{h} / B$ in 2018 for Greece, Japan, the UK and the US.

\begin{tabular}{cccccc}
\hline \hline Countries & $\begin{array}{c}\tau \\
\text { (\% of GDP) }\end{array}$ & $\begin{array}{c}s \\
\text { (\% of GDP) }\end{array}$ & $\begin{array}{c}b \\
\text { (\% of GDP) }\end{array}$ & $\begin{array}{c}\mathrm{r} \\
(\%)\end{array}$ & $\begin{array}{c}B_{h} / B \\
(\%)\end{array}$ \\
\hline Greece & 33.8 & 40 & 181.2 & 4.2 & 49 \\
Japan & 28.6 & 33 & 248.2 & 1.2 & 96 \\
UK & 35.2 & 30 & 85.2 & 1.1 & 69 \\
US & 24.3 & 36 & 105.5 & 1.7 & 52 \\
\hline \hline
\end{tabular}

Table 1: Main statistics (Source: IMF and OECD)

We consider for all countries the same discount rate $\rho=0.1$ and the same coefficient characterizing the borrowing constraint, namely $\theta=0.06 .^{10}$

Plugging these values for each country in the equations determining the steady states and the local stability properties allows to reach the following results:

- The US and UK are both characterized by the possible existence of two steady states with the lower one showing a primary surplus. The critical value of $\beta$ above which the lower steady state no longer exists for the US (UK) is $\bar{\beta} \approx 0.79$ (1.63) while the value of $\beta$ giving a proportion $B_{h} / B=0.52$ (0.69) is 1.66 (4). It follows that for both countries, the lower steady state is not admissible and they are characterized by a unique locally indeterminate equilibria. While local fluctuations can occur, there is no risk of large jumps between two BGPs. However, it is worthwhile to notice that, although close to the Euro area average, the share of US public debt hold by US resident is enough to prevent the existence of multiple equilibria. On the contrary, if the share of public debt held by UK residents was also in the average of the Euro area, the corresponding value of $\beta$ would be $1.39<\bar{\beta}$ and would not be enough to rule out the existence of the lower BGP.

- For Greece, we also find the possible existence of two steady states, the

the following categories of government liabilities (as defined in ESA 2010): currency and deposits, debt securities and loans. The general government sector comprises the subsectors: central government, state government, local government and social security funds.

${ }^{10}$ Even though this value does not satisfy Assumption 1, all our results of Propositions 1 and 2 on existence, uniqueness and multiplicity of steady states still hold. 
lower one being characterized by a primary surplus. The critical value of $\beta$ above which the lower steady state no longer exists is $\bar{\beta} \approx 20$. Considering that Greece is in the average of the Euro countries for the proportion of debt hold by domestic residents, namely $49 \%$, we can derive that the value of $\beta$ leading to $B_{h} / B=0.49$ is 6.84 . It follows that the two steady states are admissible. Our model therefore suggests that Greece is characterized by global indeterminacy with two steady states and thus the possible existence of strong fluctuations. However, the lower saddle-point steady state appears to be the focus of expectation coordination. Greece has indeed a primary surplus since 2014. Moreover, the possible large fluctuations associated to jumps between the two steady state questions the stability of the Greek debt. At the same time, this illustration shows that more optimistic expectations could coordinate on the higher steady state with larger growth, but at the cost of more local fluctuations.

- For Japan, we again find the possible existence of two steady states with the lower one characterized by a primary surplus. The critical value of $\beta$ above which the lower steady state no longer exists is $\bar{\beta} \approx 1.295$ and the value of $\beta$ giving a proportion $B_{h} / B=0.96$ is 2.17. It follows that, as for US and $\mathrm{UK}$, the lower steady state is not admissible and Japan is characterized by a unique locally indeterminate equilibria. Contrary to Greece, the uniqueness of the steady state in Japan explains why its debt level, while huge, still appears as stable. As in the case of UK, the parameter $\beta$ controlling the proportion of public debt held by domestic residents is clearly a crucial ingredient to explain this result. Indeed, if the proportion of public debt held by Japanese residents was identical to the average of the Euro area, the corresponding value of $\beta$ would be $0.57<\bar{\beta}$ and would not be enough to rule out the existence of the lower BGP.

This simple numerical illustration clearly shows that the existing crosscountry heterogeneity of debt stability could be at least partly explained by differences in the share of public debt hold by domestic residents. 


\section{Conclusion}

We have considered a small open Barro-type economy where endogenous growth is due to government spending externalities in production. We depart from the previous literature, mainly from Morimoto et al. (2016), introducing two original features: a credit constraint which limits international borrowing and a taste for domestic public debt which, in our framework, enters the utility function of households. These ingredients imply that, contrary to Morimoto at al. (2016), productive capital, domestic public debt and the international asset are not perfect substitutes. Moreover, the economy is characterized by an investment multiplier. Also, with this framework we are able to explain the observed cross country heterogeneity of the share of public debt hold by domestic residents.

Our main conclusion is that whatever the level of the debt-output ratio, there always exist a BGP featuring expectation-driven fluctuations. Moreover, while uniqueness of the BGP is ensured when the debt-output ratio is large enough, there is also a second BGP with a lower growth rate if the debt-output ratio is low enough. Hence, contrary to previous results, a lower debt does not stabilize this economy, characterized by credit market imperfections. However, a high enough taste for domestic public debt may rule out the BGP with lower growth. This result implies that if the share of

public debt hold by domestic households is high enough, global indeterminacy does not occur.

\section{Appendix}

\subsection{Proof of Proposition 1}

Using (24) and (25), we have:

$$
\begin{aligned}
\Gamma^{\prime}(x) & =\frac{r^{2}(1-\tau) s(1-s)(1-\theta) x^{-s}}{\left[r-\theta(1-\tau) s x^{1-s}\right]^{2}} \\
H^{\prime}(x) & =s \frac{x^{s-1}}{\bar{b}}
\end{aligned}
$$


In addition, we have:

$$
\begin{gathered}
\Gamma\left(x_{a}\right)=+\infty \text { and } \Gamma\left(x_{b}\right)=r-\rho>0 \\
H\left(x_{a}\right)=\frac{1}{\bar{b}}\left(\frac{r}{(1-\tau) s \theta}\right)^{\frac{s}{1-s}}+r-\frac{\tau}{\bar{b}} \text { and } H\left(x_{b}\right)=\frac{1}{\bar{b}}\left(\frac{r}{(1-\tau) s}\right)^{\frac{s}{1-s}}+r-\frac{\tau}{\bar{b}}
\end{gathered}
$$

We note that $\Gamma\left(x_{a}\right)>H\left(x_{a}\right)$ and $\Gamma\left(x_{b}\right)<H\left(x_{b}\right)$ if and only if $\bar{b}>\widehat{b}$, with $\widehat{b}$ as given by (30).

We have $\Gamma^{\prime}(x)>0$ and $H^{\prime}(x)>0$. We also easily see that $H^{\prime \prime}(x)<0$, while $\Gamma^{\prime \prime}(x)$ has the same sign than $\theta(1-\tau)(2-s) x^{1-s}-r$. Since $x>x_{b}$, $\Gamma^{\prime \prime}(x)>0$ is ensured by Assumption 1. Considering that $\Gamma(x)$ is convex and $H(x)$ is concave with $\Gamma\left(x_{a}\right)>H\left(x_{a}\right)$, there is a unique solution $x \in\left(x_{b}, x_{a}\right)$ if $\Gamma\left(x_{b}\right)<H\left(x_{b}\right)$, i.e. $\bar{b}>\widehat{b}$.

Recall finally that the existence of a steady state also requires $v^{*}>0$ which holds if and only if

$$
-\frac{\beta}{r} \frac{r-\theta(1-\tau) s x^{* 1-s}}{(1-\tau) s x^{* 1-s}-r}\left(\frac{x^{* s}-\tau}{\bar{b}}\right)<1
$$

Taking into account that $x^{*}$ does not depend on $\beta$, we conclude that if $x^{*}$ is characterized by a primary deficit, i.e. $x^{* s}-\tau>0$, then $v^{*}>0$ for any $\beta \geq 0$. On the contrary, if $x^{*}$ is characterized by a primary surplus, i.e. $x^{* s}-\tau<0$, then $v^{*}>0$ if and only if

$$
\beta<\bar{\beta} \equiv \frac{r \bar{b}}{\tau-x^{* s}} \frac{(1-\tau) s x^{* 1-s}-r}{r-\theta(1-\tau) s x^{* 1-s}}
$$

Let us study now whether the steady state is a primary deficit or a primary surplus. If $r \geqslant r_{b}$, a steady state $x>x_{b}$ satisfies $x>x_{b} \geqslant x_{0}$ and is characterized by a primary deficit. If $r \leqslant r_{a}$, a steady state $x<x_{a}$ satisfies $x<x_{a} \leqslant x_{0}$ and is characterized by a primary surplus. When $r_{a}<r<r_{b}$, then $x_{0} \in\left(x_{b}, x_{a}\right)$ and we need to analyze whether $x_{0}$ is larger or smaller than the steady state value of $x$. It is smaller than the steady state if $\Gamma\left(x_{0}\right)<$ $H\left(x_{0}\right)$. This last inequality is satisfied if and only if $Z(r)>0$, with:

$$
Z(r) \equiv r^{2}-\left(r_{b}-\rho\right) r-\rho r_{a}
$$

We derive that $Z\left(r_{a}\right)<0$ whereas $Z\left(r_{b}\right)>0$. It follows that there exists a unique

$$
r_{0}=\frac{r_{b}-\rho+\sqrt{\left(r_{b}-\rho\right)^{2}+4 \rho \theta r_{b}}}{2} \in\left(r_{a}, r_{b}\right)
$$

such that $Z(r)>0$ if and only if $r \in\left(r_{0}, r_{b}\right)$ and $Z(r)<0$ if and only if $r \in\left(r_{a}, r_{0}\right)$. All this implies that the steady state is characterized by a 
primary surplus for $r<r_{0}$ and a primary deficit for $r>r_{0}$. The Proposition immediately follows.

\subsection{Proof of Proposition 2}

If $\bar{b}<\widehat{b}$ we get $\Gamma\left(x_{b}\right)>H\left(x_{b}\right)$. As $\Gamma\left(x_{a}\right)>H\left(x_{a}\right)$, it follows that there are two steady states if there exists a $\widetilde{x} \in\left(x_{b}, x_{a}\right)$ such that $\Gamma(\widetilde{x})<H(\widetilde{x})$. Let us define

$$
\widetilde{x} \equiv\left(\frac{r}{(1-\tau) s \widetilde{\theta}}\right)^{\frac{1}{1-s}}
$$

where $\widetilde{\theta} \in(\theta, 1)$ ensures that $\widetilde{x}$ can take any value between $x_{b}$ and $x_{a} . \Gamma(\widetilde{x})<$ $H(\widetilde{x})$ is equivalent to:

$$
\left(\frac{r}{(1-\tau) s \widetilde{\theta}}\right)^{\frac{s}{1-s}}-\tau>\bar{b}\left[r \frac{1-\widetilde{\theta}}{\widetilde{\theta}-\theta}-\rho\right]
$$

Assume from now on that $\rho<\rho_{0}$ with

$$
\rho_{0} \equiv r \frac{1-\widetilde{\theta}}{\widetilde{\theta}-\theta}
$$

so that the right-hand side (RHS) is positive. Note that the left-hand side (LHS) is equal to 0 for $r=\widetilde{r}$. Then, it is easy to check that inequality (38) is satisfied if $r>\widetilde{r}$ and $b<\widetilde{b}$. Consider then from (24)-(25) that $\partial \Gamma(x) / \partial r<0$ and $\partial H(x) / \partial r>0$. Using also the fact that for a given $\bar{b}<\widetilde{b}, \lim _{r \rightarrow \widetilde{r}} \widetilde{b}=0$ and the condition $\bar{b}<\widetilde{b}$ is necessarily violated as $r$ is approaching $\widetilde{r}$, we conclude that there exists $\underline{r} \in\left(\widetilde{r}, r_{b}\right)$ such that there are two stationary solutions $x_{1}, x_{2} \in\left(x_{b}, x_{a}\right)$, with $x_{1}<x_{2}$ if $\bar{b}<\min \{\widetilde{b}, \widehat{b}\}$ and $r \in\left(\underline{r}, r_{b}\right)$. It is worth noting that if $r=\underline{r}$, then there is a unique associated steady state $x_{1}=x_{2}=\underline{x}$ since $\underline{x}$ is such that $\Gamma(\underline{x})=H(\underline{x})$ and $\Gamma^{\prime}(\underline{x})=H^{\prime}(\underline{x})$.

Let us study now whether the steady states are characterized by a primary deficit or a primary surplus. Using the proof of Proposition $1, \Gamma\left(x_{0}\right)=H\left(x_{0}\right)$ if and only if there is a solution $r_{0} \in\left(\widetilde{r}, r_{b}\right)$ solving $Z\left(r_{0}\right)=0$. We know that $Z\left(r_{b}\right)>0$. Using $(36)$ and the fact that $r_{a}=\theta r_{b}$ and $\widetilde{r}=\widetilde{\theta} r_{b}$, we get:

$$
Z(\widetilde{r})=-r_{b}\left[r_{b} \tilde{\theta}(1-\widetilde{\theta})-\rho(\widetilde{\theta}-\theta)\right]
$$

which is negative for $\rho$ such that

$$
\rho<\rho_{1} \equiv \frac{r_{b} \widetilde{\theta}(1-\widetilde{\theta})}{\widetilde{\theta}-\theta}
$$


This means that the expression (37) is such that $r_{0} \in\left(\widetilde{r}, r_{b}\right)$ with $\Gamma\left(x_{0}\right)<$ $H\left(x_{0}\right)$ if and only if $r \in\left(r_{0}, r_{b}\right)$ and $\Gamma\left(x_{0}\right)>H\left(x_{0}\right)$ if and only if $r \in\left(\widetilde{r}, r_{0}\right)$. We need now to locate $r_{0}$ with respect to $\underline{r}$. We know that $\underline{r}$ is such that the associated steady state $\underline{x}$ satisfies $\Gamma(\underline{x})=H(\underline{x})$ and $\Gamma^{\prime}(\underline{x})=H^{\prime}(\underline{x})$. Considering from (34)-(35) that $\partial \Gamma^{\prime}(x) / \partial r<0$ and $\partial H(x)^{\prime} / \partial r=0$, we derive that if $\Gamma^{\prime}\left(x_{0}\right)<H^{\prime}\left(x_{0}\right)$, we must have $\underline{r}<r_{0} . \Gamma^{\prime}\left(x_{0}\right)<H^{\prime}\left(x_{0}\right)$ is equivalent to:

$$
r_{b}-r_{a}<\left(\frac{r-r_{a}}{r}\right)^{2} \frac{s \tau}{\bar{b}(1-s)}
$$

Note that $r_{a}=\theta r_{b}$. Using (36), we derive that if $\rho=0$, then $r_{0}=r_{b}$. Substituting these expressions in (39) for $r=r_{0}$, we obtain that this inequality is satisfied if $\bar{b}<b_{1}$, with:

$$
b_{1} \equiv \frac{(1-\theta) s \tau}{(1-s) r_{b}}
$$

By continuity, there exists $\rho_{2}>0$ such that when $\rho \in\left(0, \rho_{2}\right)$, there is a bound $b^{*}$ close to $b_{1}$ such that when $b<b^{*}, \Gamma^{\prime}\left(x_{0}\right)<H^{\prime}\left(x_{0}\right)$ for $r=r_{0}$ and thus $\underline{r}<r_{0}$. Let us then denote $\bar{\rho}=\min \left\{\rho_{0}, \rho_{1}, \rho_{2}\right\}$. Therefore, if $\rho \in(0, \bar{\rho})$ and $\bar{b}<\min \left\{\widetilde{b}, \widehat{b}, b^{*}\right\}$, we conclude that for $r \in\left(r_{0}, r_{b}\right)$, the steady state $x_{2}\left(>x_{0}\right)$ is characterized by a primary deficit and $x_{1}\left(<x_{0}\right)$ by a primary surplus while for $r \in\left(\underline{r}, r_{0}\right)$, we have $x_{0}<x_{1}<x_{2}$ and the two steady states are characterized by primary deficit. The results of the Proposition follow imposing $\bar{b}^{\max } \equiv \min \left\{\widetilde{b}, \widehat{b}, b^{*}\right\}$.

\subsection{Welfare evaluated at a BGP}

Using the utility function and equation (18), the welfare can be written:

$$
W=\int_{t=0}^{+\infty} e^{-\rho t}[(1+\beta) \ln c(t)+\beta \ln \widetilde{B}(x(t))] d t
$$

with:

$$
\widetilde{B}(x(t)) \equiv \frac{B_{h}(t)}{c(t)}=\frac{\beta}{r}\left(\frac{r-\theta(1-\tau) s x(t)^{1-s}}{(1-\tau) s x(t)^{1-s}-r}\right)
$$

Using the consumption growth rate, (40) is equivalent to:

$$
W=\int_{t=0}^{+\infty} e^{-\rho t}\left[(1+\beta) \ln \left(c(0) e^{\int_{0}^{t} \Gamma(x(i)) d i}\right)+\beta \ln \widetilde{B}(x(t))\right] d t
$$


Along a BGP, this implies that:

$$
\begin{aligned}
W & =\int_{t=0}^{+\infty} e^{-\rho t}[(1+\beta)(\ln c(0)+\Gamma(x) t)+\beta \ln \widetilde{B}(x)] d t \\
& =\left[-\frac{1}{\rho} e^{-\rho t}\right]_{0}^{+\infty}[(1+\beta) \ln c(0)+\beta \ln \widetilde{B}(x)]+\Gamma(x)(1+\beta) \int_{t=0}^{+\infty} e^{-\rho t} t d t \\
& =\frac{1}{\rho}[(1+\beta) \ln c(0)+\beta \ln \widetilde{B}(x)] \\
& +\Gamma(x)(1+\beta)\left\{\left[-\frac{1}{\rho} e^{-\rho t} t\right]_{0}^{+\infty}-\int_{t=0}^{+\infty}\left(-\frac{1}{\rho} e^{-\rho t}\right) d t\right\} \\
& =\frac{1}{\rho}[(1+\beta) \ln c(0)+\beta \ln \widetilde{B}(x)]-\Gamma(x) \frac{1+\beta}{\rho^{2}}\left\{\left[\rho e^{-\rho t} t\right]_{0}^{+\infty}+\left[e^{-\rho t} t\right]_{0}^{+\infty}\right\} \\
& =\frac{1}{\rho^{2}}[(1+\beta) \Gamma(x)+\rho((1+\beta) \ln c(0)+\beta \ln \widetilde{B}(x))]
\end{aligned}
$$

To determine $c(0)$, we use the budget constraint (3) and the binding borrowing constraint (4) evaluated at a BGP to get:

$$
c+(\Gamma(x)-r) B_{h}=(1-\tau) w+(1-\tau)(1-\theta) r_{k} k-\Gamma(x) k\left(1-\theta \frac{(1-\tau) r_{k}}{r}\right)
$$

Using (1), (2), (24) and (41), we deduce that $c(0)$ is given by (32), and substituting it into (43), we get an expression of the welfare which depends on the level of $x$ at the BGP, the initial condition $k(0)>0$ and parameters.

\subsection{Proof of Proposition 3}

Since $H(x)=\Gamma(x)$ at a steady state and $\bar{b}$ only enters $H(x)$, we have:

$$
\frac{d x}{d \bar{b}}=\frac{\partial H / \partial \bar{b}}{\Gamma^{\prime}(x)-H^{\prime}(x)}
$$

Note that $\Gamma^{\prime}(x)<H^{\prime}(x)$ when $x=x_{1}$ and $\Gamma^{\prime}(x)>H^{\prime}(x)$ when $x=x_{2}$. Moreover, the sign of $\partial H / \partial \bar{b}$ is given by the sign of $\tau-x^{s}$. Using Propositions 1 and 2, Proposition 3 immediately follows. 


\subsection{Proof of Proposition 4}

Linearizing the dynamical system (33) around a steady state $\left(\bar{b}, v^{*}, x^{*}\right)$ gives the following Jacobian matrix

$$
\mathcal{J}=\left(\begin{array}{ccc}
-\phi & 0 & 0 \\
V_{1}\left(\bar{b}, x^{*}\right) v^{*} & 0 & V_{2}\left(\bar{b}, x^{*}\right) v^{*} \\
X_{1}\left(\bar{b}, v^{*}, x^{*}\right) x^{*} & X_{2}\left(\bar{b}, v^{*}, x^{*}\right) x^{*} & X_{3}\left(\bar{b}, v^{*}, x^{*}\right) x^{*}
\end{array}\right)
$$

We easily derive

$$
\begin{aligned}
\mathcal{D} & =\phi X_{2}\left(\bar{b}, v^{*}, x^{*}\right) V_{2}\left(\bar{b}, x^{*}\right) x^{*} v^{*} \\
\mathcal{T} & =-\phi+X_{3}\left(\bar{b}, v^{*}, x^{*}\right) x^{*} \\
\mathcal{S} & =-X_{2}\left(\bar{b}, v^{*}, x^{*}\right) V_{2}\left(\bar{b}, x^{*}\right) x^{*} v^{*}-\phi X_{3}\left(\bar{b}, v^{*}, x^{*}\right) x^{*}
\end{aligned}
$$

It follows that the eigenvalues of $\mathcal{J}$ are solution of the following polynomial

$$
\begin{aligned}
\mathcal{P}(\lambda) & =\lambda^{3}-\mathcal{T} \lambda^{2}+\mathcal{S} \lambda-\mathcal{D} \\
& =(\lambda+\phi)\left[\lambda^{2}-\lambda X_{3}\left(\bar{b}, v^{*}, x^{*}\right) x^{*}-X_{2}\left(\bar{b}, v^{*}, x^{*}\right) V_{2}\left(\bar{b}, x^{*}\right) x^{*} v^{*}\right]
\end{aligned}
$$

We then get three eigenvalues $\left(\lambda_{1}, \lambda_{2}, \lambda_{3}\right)$ such that

$$
\begin{aligned}
\lambda_{1} & =-\phi \\
\lambda_{2}+\lambda_{3} & =X_{3}\left(\bar{b}, v^{*}, x^{*}\right) x^{*} \\
\lambda_{2} \lambda_{3} & =-X_{2}\left(\bar{b}, v^{*}, x^{*}\right) V_{2}\left(\bar{b}, x^{*}\right) x^{*} v^{*}
\end{aligned}
$$

Straightforward computations give

$$
X_{2}\left(\bar{b}, v^{*}, x^{*}\right)=\frac{-r v^{*} x^{* 1-s}\left\{\left(\frac{\beta}{r} \frac{r-\theta(1-\tau) s x^{* 1-s}}{(1-\tau) s x^{* 1-s}-r}\right)\left[1-\frac{\Gamma\left(x^{*}\right)}{r}\right]-\frac{1}{r}\right\}}{(1-s)\left[1+\beta v^{*} x^{* 1-s} \frac{(1-\theta)(1-\tau) s x^{* 1-s}}{\left[(1-\tau) s x^{* 1-s}-r\right]^{2}}\right]}
$$

with

$$
\Gamma\left(x^{*}\right)=\frac{r(1-\theta)(1-\tau) s x^{* 1-s}}{r-\theta(1-\tau) s x^{* 1-s}}-\rho
$$

Note that at the steady state we get

$$
\begin{aligned}
& (1-\tau)(1-\theta s) x^{* 1-s}-\left(\frac{r-\theta(1-\tau) s x^{* 1-s}}{r}\right) \Gamma\left(x^{*}\right) \\
= & -r v^{*} x^{* 1-s}\left\{\left(\frac{\beta}{r} \frac{r-\theta(1-\tau) s x^{* 1-s}}{(1-\tau) s x^{* 1-s}-r}\right)\left[1-\frac{\Gamma\left(x^{*}\right)}{r}\right]-\frac{1}{r}\right\}
\end{aligned}
$$

We then get after simplifications 


$$
X_{2}\left(\bar{b}, v^{*}, x^{*}\right)=\frac{\left[(1-\tau) x^{* 1-s}(1-\theta s)-\Gamma\left(x^{*}\right) \frac{r-\theta s(1-\tau) x^{* 1-s}}{r}\right] \frac{1}{v^{*}}}{(1-s)\left[1+\beta v^{*} x^{* 1-s} \frac{(1-\theta)(1-\tau) s x^{* 1-s}}{\left[(1-\tau) s x^{* 1-s}-r\right]^{2}}\right]}
$$

Since $\theta<1$, we get for any $x^{*}$

$$
\begin{aligned}
(1-\tau) x^{* 1-s}(1-\theta s)-\Gamma\left(x^{*}\right) \frac{r-\theta s(1-\tau) x^{* 1-s}}{r} & =(1-\tau)(1-s) x^{* 1-s} \\
& +\rho \frac{r-\theta s(1-\tau) x^{* 1-s}}{r}>0
\end{aligned}
$$

and

$$
\frac{r(1-\theta)}{\left[r-\theta(1-\tau) s x^{* 1-s}\right]\left[(1-\tau) s x^{* 1-s}-r\right]}>0
$$

Recall finally that $v^{*}>0$ is ensured by $\beta \in(0, \bar{\beta})$ with $\bar{\beta}=+\infty$ if the steady state is characterized by a primary surplus. It follows that $X_{2}\left(\bar{b}, v^{*}, x^{*}\right)>0$ for any $x^{*}$. Notice now that

$$
V_{2}\left(\bar{b}, x^{*}\right)=\Gamma^{\prime}\left(x^{*}\right)-H^{\prime}\left(x^{*}\right)
$$

We have shown previously that if $\bar{b}>\hat{b}$, there exists a unique steady state that is necessarily such that $\Gamma^{\prime}\left(x^{*}\right)-H^{\prime}\left(x^{*}\right)>0$. In such a case, we conclude that $V_{2}\left(\bar{b}, x^{*}\right)>0$ and thus $\lambda_{2} \lambda_{3}<0$. It follows that $\lambda_{2}>0$ and $\lambda_{3}<0$. Since $\lambda_{1}=-\phi<0$, we conclude that two eigenvalues are negative and one is positive implying that the steady state is locally indeterminate.

Let us finally consider the case with $\bar{b}<\hat{b}$ where two steady states $x_{1}^{*}<x_{2}^{*}$ exist and are necessarily such that $\Gamma^{\prime}\left(x_{1}^{*}\right)-H^{\prime}\left(x_{1}^{*}\right)<0$ and $\Gamma^{\prime}\left(x_{2}^{*}\right)-H^{\prime}\left(x_{2}^{*}\right)>$ 0 . It follows that the highest steady state $x_{2}^{*}$ satisfies $V_{2}\left(\bar{b}, x_{2}^{*}\right)>0$, and we conclude again that two eigenvalues are negative and one is positive implying local indeterminacy.

Let us consider now the lowest steady state $x_{1}^{*}$ which is such that $V_{2}\left(\bar{b}, x_{2}^{*}\right)>0$ implying $\lambda_{2} \lambda_{3}>0$. We need then to study the sign of $\lambda_{2}+\lambda_{3}$ and thus to compute $X_{3}\left(\bar{b}, v^{*}, x^{*}\right)$. Let us write $X\left(\bar{b}, v^{*}, x^{*}\right)$ as follows

$$
X\left(\bar{b}, v^{*}, x^{*}\right)=\frac{\Phi\left(x^{*}\right)}{(1-s)\left[1+\beta v^{*} x^{* 1-s} \frac{(1-\theta)(1-\tau) s x^{* 1-s}}{\left[(1-\tau) s x^{* 1-s}-r\right]^{2}}\right]}
$$

with $\Phi(x)=\mathcal{A}(x) \mathcal{B}(x)-(1-\tau)(1-\theta s) x^{1-s}-r v x^{1-s} \mathcal{C}(x)$, and

$$
\begin{aligned}
\mathcal{A}(x) & =\frac{x^{s}-\tau}{\bar{b}}+r+\phi\left(1-\frac{\bar{b}}{b}\right) \\
\mathcal{B}(x) & =\frac{r-\theta s(1-\tau) x^{1-s}}{r} \\
\mathcal{C}(x) & =\left(\frac{\beta}{r} \frac{r-\theta(1-\tau) s x^{1-s}}{(1-\tau) s x^{1-s}-r}\right)\left[1-\frac{\Gamma(x)}{r}\right]-\frac{1}{r}
\end{aligned}
$$


Recall that at the steady state $\bar{b}=b$. We obviously get

$$
X_{3}\left(\bar{b}, v^{*}, x^{*}\right)=\frac{\Phi^{\prime}\left(x^{*}\right)}{(1-s)\left[1+\beta v^{*} x^{* 1-s} \frac{(1-\theta)(1-\tau) s x^{* 1-s}}{\left[(1-\tau) s x^{* 1-s}-r\right]^{2}}\right]}
$$

which sign is given by the sign of $\Phi^{\prime}\left(x^{*}\right)$ when $\beta \in(0, \bar{\beta})$.

We have already shown above that $\mathcal{C}\left(x^{*}\right)<0$. Considering that at the steady state

We easily derive

$$
1-\frac{\Gamma\left(x^{*}\right)}{r}=-\frac{x^{* s}-\tau}{r \bar{b}}
$$

$$
\begin{aligned}
& \mathcal{A}^{\prime}\left(x^{*}\right)=s \frac{x^{* s-1}}{\bar{b}}>0 \\
& \mathcal{B}^{\prime}\left(x^{*}\right)=-\frac{\theta(1-s) s(1-\tau) x^{*-s}}{r}<0 \\
& \mathcal{C}^{\prime}\left(x^{*}\right)=\beta \frac{(1-\theta)(1-s)(1-\tau) s x^{*-s}\left[\frac{x^{* s}-\tau}{r \bar{b}}\left[r-\theta(1-s) s x^{* 1-s}\right]-\left[(1-\tau) s x^{* 1-s}-r\right]\right]}{\left[(1-\tau) s x^{* 1-s}-r\right]^{2}\left[r-\theta(1-s) s x^{* 1-s}\right]}
\end{aligned}
$$

From this we can compute

$$
\begin{aligned}
\Phi^{\prime}\left(x^{*}\right) & =\mathcal{A}^{\prime}\left(x^{*}\right) \mathcal{B}\left(x^{*}\right)+\mathcal{A}\left(x^{*}\right) \mathcal{B}^{\prime}\left(x^{*}\right)-(1-s)(1-\tau)(1-\theta s) x^{*-s} \\
& -(1-s) r v x^{*-s} \mathcal{C}(x)-r v x^{* 1-s} \mathcal{C}^{\prime}\left(x^{*}\right)
\end{aligned}
$$

At the steady state we get $\Phi\left(x^{*}\right)=0$ which implies when $\beta \in(0, \bar{\beta})$

$$
-r v^{*} x^{* 1-s} \mathcal{C}\left(x^{*}\right)=(1-\tau)(1-\theta s) x^{* 1-s}-\mathcal{A}\left(x^{*}\right) \mathcal{B}\left(x^{*}\right)>0
$$

Substituting this into the previous expression yields

$$
\Phi^{\prime}\left(x^{*}\right)=\mathcal{A}^{\prime}\left(x^{*}\right) \mathcal{B}\left(x^{*}\right)+\mathcal{A}\left(x^{*}\right)\left[\mathcal{B}^{\prime}\left(x^{*}\right)-\frac{(1-s)}{x^{*}} \mathcal{B}\left(x^{*}\right)\right]-r v x^{* 1-s} \mathcal{C}^{\prime}\left(x^{*}\right)
$$

Considering that

$$
\begin{aligned}
\mathcal{B}^{\prime}\left(x^{*}\right)-\frac{(1-s)}{x^{*}} \mathcal{B}\left(x^{*}\right) & =-\frac{\theta(1-s) s(1-\tau) x^{*-s}}{r}-\frac{(1-s)}{x^{*}} \frac{r-\theta s(1-\tau) x^{* 1-s}}{r} \\
& =-\frac{(1-s)}{x^{*}}
\end{aligned}
$$

we get

$$
\Phi^{\prime}\left(x^{*}\right)=\mathcal{A}^{\prime}\left(x^{*}\right) \mathcal{B}\left(x^{*}\right)-\frac{(1-s)}{x^{*}} \mathcal{A}\left(x^{*}\right)-r v x^{* 1-s} \mathcal{C}^{\prime}\left(x^{*}\right)
$$

Recalling that for any steady state we have $\Gamma\left(x^{*}\right)=\mathcal{A}\left(x^{*}\right), H^{\prime}\left(x^{*}\right)=\mathcal{A}^{\prime}\left(x^{*}\right)$,

$$
\Gamma^{\prime}\left(x^{*}\right)=\frac{(1-s) r}{x^{*}\left[r-\theta(1-\tau) s x^{* 1-s}\right]}\left[\Gamma\left(x^{*}\right)+\rho\right]
$$

and that $x_{1}^{*}$ is necessarily such that $\Gamma^{\prime}\left(x_{1}^{*}\right)-H^{\prime}\left(x_{1}^{*}\right)<0$. We then derive

$$
\Phi^{\prime}\left(x_{1}^{*}\right)>\frac{(1-s) \rho}{x_{1}^{*}}-r v x^{* 1-s} \mathcal{C}^{\prime}\left(x_{1}^{*}\right)
$$


We immediately see from $(45)$ that $\mathcal{C}^{\prime}\left(x_{1}^{*}\right)<0$ if and only if

$$
\frac{x_{1}^{* s}-\tau}{r \bar{b}}\left[r-\theta(1-s) s x_{1}^{* 1-s}\right]-\left[(1-\tau) s x_{1}^{* 1-s}-r\right] \equiv g\left(x_{1}^{*}\right)<0
$$

To analyze the sign of $g\left(x^{*}\right)$ consider the steady-state equation (23) that can be rewritten as follows

$$
\frac{r(1-\tau) s x^{* 1-s}(1-\theta)}{r-\theta(1-\tau) s x^{* 1-s}}-\rho=r\left(\frac{s_{1}^{* s}-\tau}{r \bar{b}}+1\right)
$$

or equivalently

$$
\frac{s_{1}^{* s}-\tau}{r \bar{b}}\left[r-\theta(1-\tau) s x_{1}^{* 1-s}\right]=(1-\tau) s x_{1}^{* 1-s}-r-\frac{\rho}{r}\left[r-\theta(1-\tau) s x_{1}^{* 1-s}\right]
$$

It follows therefore that

$$
g\left(x_{1}^{*}\right)=-\frac{\rho}{r}\left[r-\theta(1-\tau) s x^{* 1-s}\right]<0
$$

and thus $\mathcal{C}^{\prime}\left(x_{1}^{*}\right)<0$. As a result, $\Phi^{\prime}\left(x_{1}^{*}\right)>0$ or equivalently $X_{3}\left(\bar{b}, v_{1}^{*}, x_{1}^{*}\right)>0$. Since $V_{2}\left(\bar{b}, x_{1}^{*}\right)<0$, we conclude that one eigenvalue is negative and two eigenvalues have a positive real part. It follows that $x_{1}^{*}$ is saddle-point stable.

\section{References}

[1] Barro, R. (1990): "Government Spending in a Simple Model of Endogenous Growth," Journal of Political Economy 98, 103-125.

[2] Chéron, A., K. Nishimura, C. Nourry, T. Seegmuller and A. Venditti (2019): "Growth and Public Debt: What Are the Relevant Trade-Offs?," Journal of Money, Credit and Banking 51, 655-682.

[3] Chung, K. and S.J. Turnovsky (2010): "Foreign Debt Supply in an Imperfect International Capital Market: Theory and Evidence," Journal of International Money and Finance 29, 201-223.

[4] Collard, F., M. Habib, and J.-C. Rochet. (2015): "Sovereign Debt Sustainability in Advanced Economies," Journal of the European Economic Association 13, 381-420.

[5] Fahri, E. and J. Tirole (2012): "Bubbly Liquidity," Review of Economic Studies 79, 678-706. 
[6] Futagami, K. , T. Iwaisako and R. Ohdoi (2008): "Debt Policy Rule, Productive Government Spending, and Multiple Growth Paths," Macroeconomic Dynamics 12, 445-462.

[7] Hirano, T. and N. Yanagawa (2017): "Asset Bubbles, Endogenous Growth, and Financial Frictions," Review of Economic Studies 84, 406443.

[8] Kiyotaki, N. and J. Moore (1997): "Credit Cycles," Journal of Political Economy 105, 211-248.

[9] Maebayashi, N., T. Hori and K. Futagami (2017): "Dynamic Analysis of Reductions in Public Debt in an Endogenous Growth Model with Public Capital," Macroeconomic Dynamics 21, 1454-1483.

[10] Manova, K. (2008): "Credit Constraints, Equity Market Liberalizations and International Trade," Journal of International Economics 76, 33-47.

[11] Minea, A. and P. Villieu (2013): "Debt Policy Rule, Productive Government Spending, and Multiple Growth Paths: a Note," Macroeconomic Dynamics 17, 947-954.

[12] Morimoto, K., T. Hori, N. Maebayashi and K. Futagami (2017): "Debt Policy Rules in an Open Economy," Journal of Public Economic Theory 19, 158-177.

[13] Reinhart, C., and K. Rogoff. (2010): "Growth in a Time of Debt," American Economic Review 100, 573-578. 